\title{
TWO-DIMENSIONAL SPREADING AND THICKENING OF AUFEIS
}

\author{
By G.A. SCHOHL \\ (Engineering Laboratory, Tennessee Valley Authority, Norris, Tennessee 37828, U.S.A.) \\ and R. ETTEMA
}

(Iowa Institute of Hydraulic Research, Department of Civil and Environmental Engineering, The

University of Iowa, Iowa City, Iowa 52242, U.S.A.)

ABSTRACT. The growth of two-dimensional, or laterally confined (flume), aufeis is shown from laboratory data to depend primarily on seven, independent, dimensionless parameters. During the early, two-dimensional, phase of its growth, aufeis consists of a mixture of ice and water, or ice-water slush, forming on a frigid base. Its early growth depends on four parameters: those expressing position along aufeis, period of spreading, slope of frigid base over which aufeis forms, and magnitude of heat flux to air from the surface of aufeis relative to latent heat release during freezing. The influences of two of the three remaining parameters, those expressing magnitude of heat flux to air relative to heat flux to frigid base and confined width of aufeis growth, are not felt until after a transition time has passed. The transition time apparently coincides with the beginning of the processes by which the ice-water slush on the surface of aufeis freezes solid. After a slush layer on aufeis begins to freeze solid, a new slush layer forms over its frozen surface. The continuing, cyclic process by which slush layers form and eventually freeze results in the ice laminations that are a feature of aufeis. The influence of the seventh governing parameter, a Reynolds number, cannot be discerned in the laboratory data.

\section{NOMENCLATURE}

Water or slush depth on the surface of aufeis

Designator for "function of"

Acceleration of gravity

Streamwise spread length of aufeis

Equilibrium length of two-dimensional aufeis

Equilibrium length if $\phi_{\mathrm{i}}$ is neglected in expression for $\ell_{e}$

Latent heat of water fusion

Total mass per unit width of aufeis

Water discharge per unit width

Total water discharge

Reynolds number

Total thickness of aufeis

Longitudinal slope of refrigerated flume

Time

Time-scale coresponding to length scale $\ell_{\mathrm{e}}$

Time at which aufeis length reaches $\ell$

Time-scale corresponding to length scale $\ell_{S}$

Temperature

Width of refrigerated flume

Longitudinal coordinate

Vertical coordinate

Thermal diffusivity

Thickness of aufeis underlying surface layer of slush
Critical depth in wide channel

$\begin{array}{ll}\rho & \text { Density } \\ v & \text { Kinematic viscosity } \\ \phi_{\mathrm{i}} & \text { Heat flux from aufeis to base } \\ \phi_{\mathrm{wa}} & \text { Heat flux from aufeis to air } \\ \phi_{\mathrm{r}} & \text { Ratio of } \phi_{\mathrm{wa}} \text { to }\left(\phi_{\mathrm{wa}}+\phi_{\mathrm{i}}\right) \\ \psi & \text { General dependent variable }\end{array}$

Subscripts and superscripts

a Air

b Frigid base

f Freezing

i Ice

$0 \quad$ Value of variable at $x=0$ or $t=0$

s Water surface

w Water

* $\quad$ Normalized quantity

\section{INTRODUCTION}

Small-scale aufeis formations were observed and monitored as they grew under conditions of steady discharge and heat-flux rates in a recirculating flume located in a refrigerated laboratory at the Iowa Institute of Hydraulic Research (IIHR). In a previous paper, Schohl and Ettema (1986b) presented basic theoretical concepts, including appropriate length and time scales, and a detailed, composite description of the processes associated with aufeis growth. The present paper, a continuation of that paper, presents laboratory data on the spreading and thickening of aufeis in terms of seven significant independent, dimensionless parameters that influence aufeis growth. The forms of the key parameters are determined from theory and dimensional analysis.

Aufeis formations (also referred to as naleds or icings) are spreading and thickening ice accretions that grow in cold winter air when a shallow flow of water streams over a river ice cover, or over frozen ground, and freezes progressively to it. They can form initially on any frigid surface, but their subsequent growth always preceeds as a progressive accretion of ice. Aufeis begins forming when an insulated flow path under an ice cover or under ground is interrupted, causing water to emerge at the surface and flow in frigid air. In cross-section, aufeis is typically laminated, as evident in Figure 1.

Aufeis formations have long been of interest and concern to scientists and engineers because they cause a variety of engineering problems. For example, they may block drainage facilities, causing subsequent spring flooding and wash-outs of embankments; they may inundate roads, railroads, and airfields causing them to become unusable; 


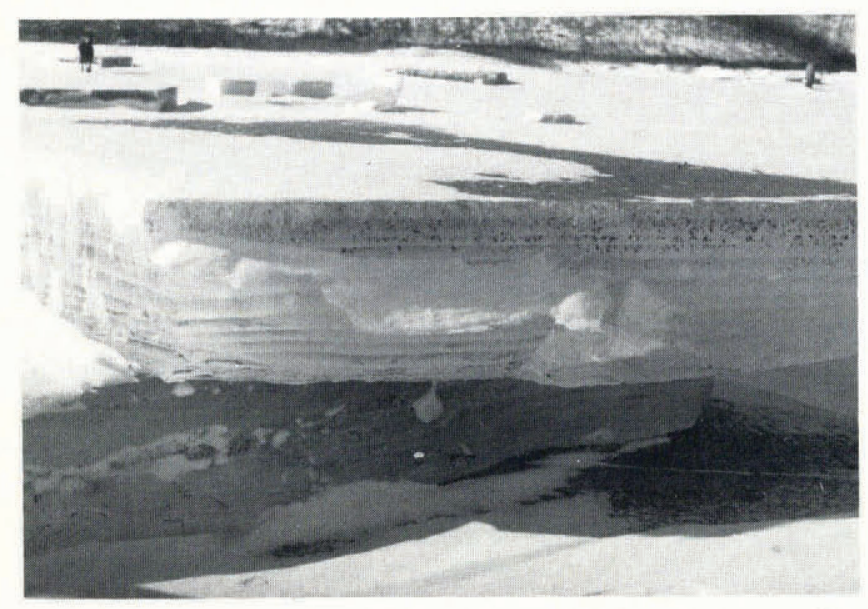

Fig. 1. A block of aufeis formed on a shallow river. Note the ice laminations. they may engulf bridges spanning streams; they may threaten flood-plain communities and individual homes; and they may disrupt operation of tunnels and mines. Further information about aufeis formations occurring in Nature and the problems they cause has been provided by Schohl and Ettema (1986a, b), Ashton (1986), Kane (1981), Carey (1973), and Alekseyev and others (1973).

\section{EXPERIMENTS}

Aufeis was grown in a $0.60 \mathrm{~m}$ wide, $0.30 \mathrm{~m}$ deep, and $12 \mathrm{~m}$ long refrigerated, tilting flume. As aufeis spread and thickened down-stream along the flume, the profiles of the water and ice associated with it were recorded. Figure 2 illustrates schematically a simplified, or idealized, aufeis formation in the refrigerated flume. Because its longitudinal cross-section is invariant across the width of the flume, and its shape is defined by a typical longitudinal, twodimensional cross-section, the aufeis formation in Figure 2 may be considered two-dimensional. In the experiments,

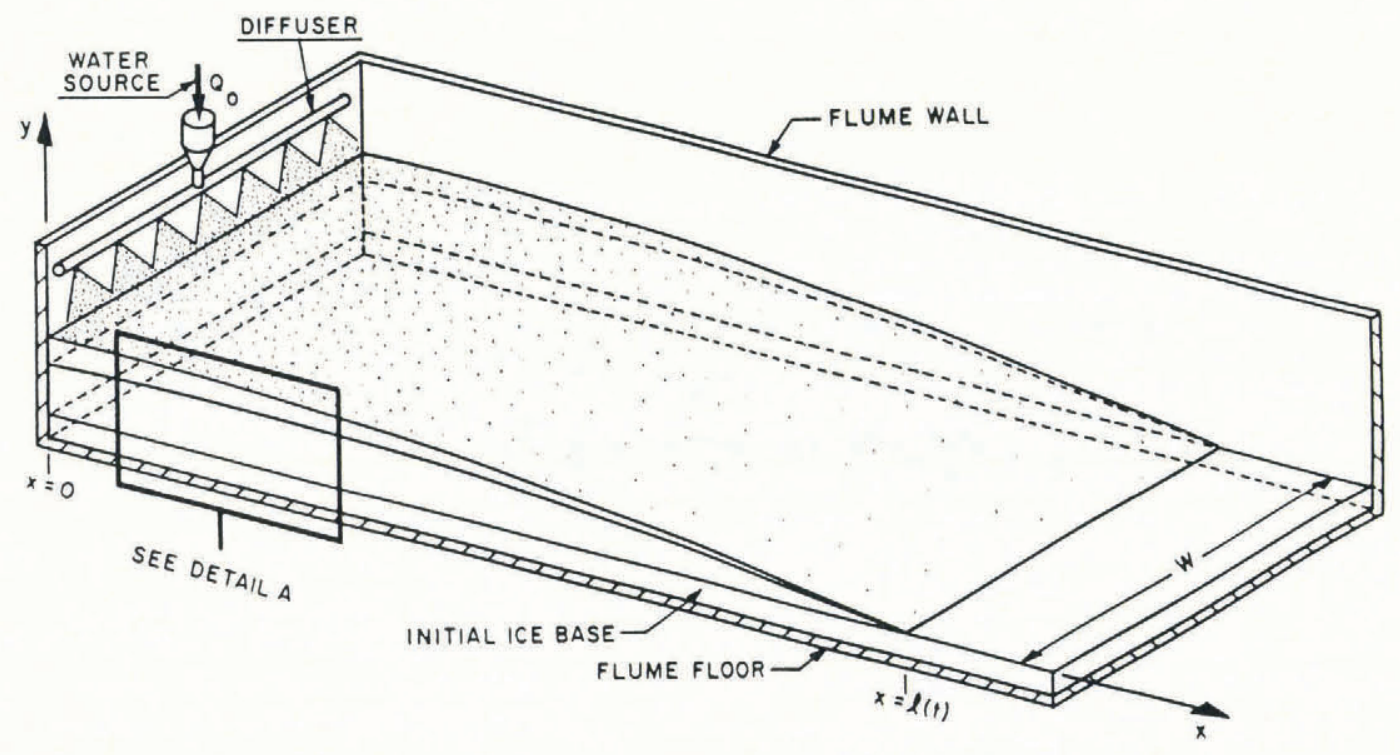

DETAIL A

(NOT TO SCALE)

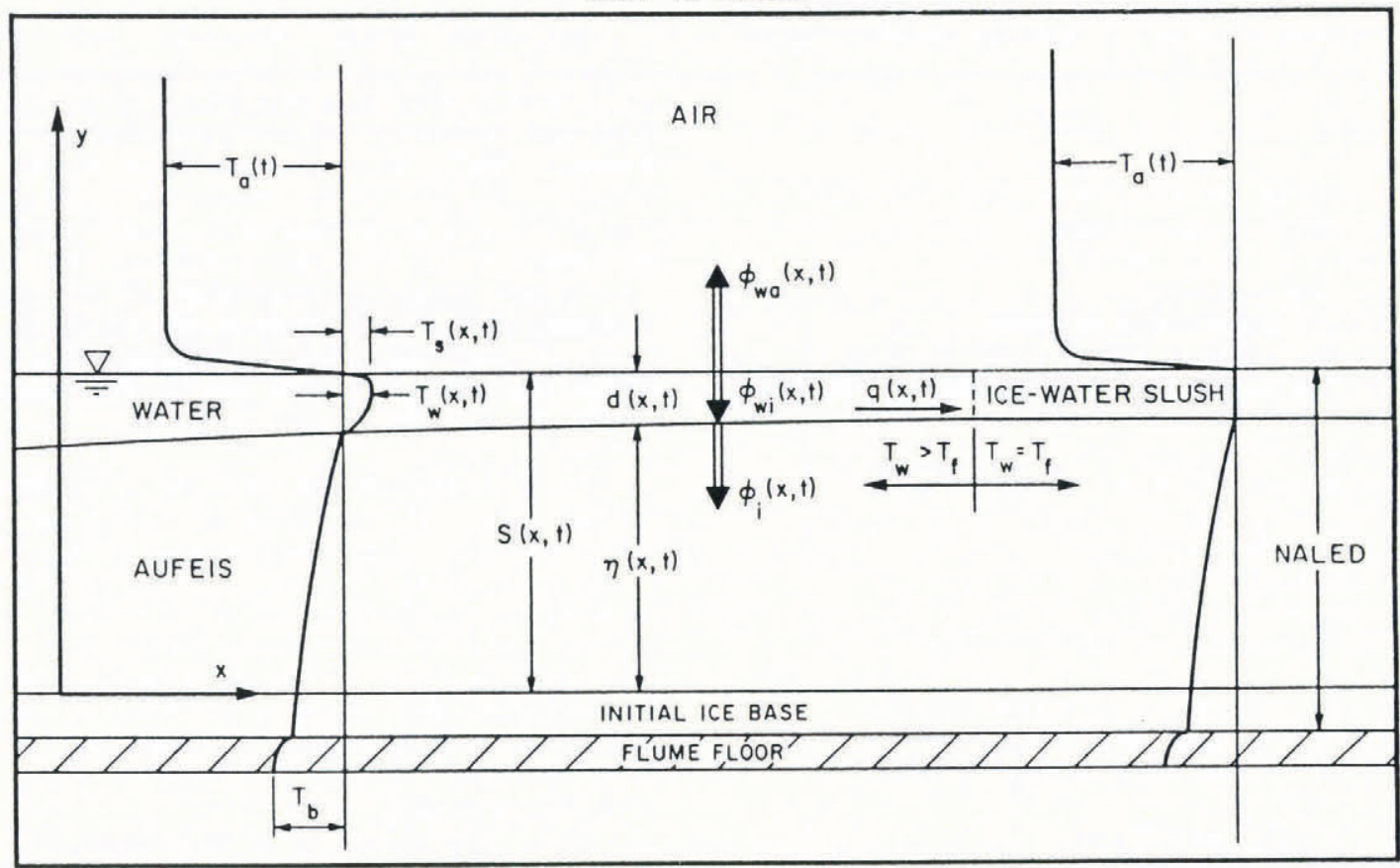

Fig. 2. Schematic of two-dimensional aufeis formation in the refrigerated flume. Detail A shows the principal variables associated with aufeis formation. 
aufeis spread and thickened in a complex, layer-by-layer manner. The early phase of its growth was two-dimensional, but its later growth was influenced by three-dimensional, or boundary, effects.

Figure 2 also illustrates many of the dependent and independent variables associated with aufeis growth. The variables controlled during the experiments include the source-water discharge, $Q_{0}$; the source-water temperature, $T_{\text {wo }}$; the air temperature, $T_{\mathrm{a}}$ (or heat flux, $\phi_{\mathrm{wa}}$ ); the flume-floor (circulating coolant) temperature, $T_{\mathrm{b}}$ (or heat flux, $\left.\phi_{\mathrm{i}}(x, 0)\right)$; and the flume slope, $S_{0}$. The dependent variables measured during the experiments include the spread length, $\ell(t)$, the thickness of the surface layer of water or slush, $d(x, t)$, and the thickness of aufeis underlying the surface layer, $n(x, t)$.

For each experiment conducted (36 total), Table I lists the values maintained for the controlled variables, the corresponding values of the key heat-flux components, and the values of four normalization scales (defined in subsequent sections). The heat flux $\phi_{\text {io }}$ refers to the initial value of the heat flux, $\phi_{i}$, from the water-ice interface into the underlying aufeis. This heat flux varied with both distance, $x$, and time, $t$, during the experiments, because in addition to depending on the flume floor temperature, $T_{\mathrm{b}}$, it depends on the thickness of the initial ice base and on the thickness of aufeis, $n(x, t)$. One controlled variable not included in Table $I$ is the source-water temperature. For all of the experiments, the temperature of the water supplied to the diffuser was maintained between about $1^{\circ}$ and $3^{\circ} \mathrm{C}$.
Because the water cooled as it flowed through the diffuser, the temperature, $T_{w 0}$, of the water in the pool under the diffuser was maintained between $0^{\circ}$ and $0.5^{\circ} \mathrm{C}$. All data obtained from the experiments have been documented by Schohl and Ettema (1986a).

Aufeis growth was initiated by introducing source water to the diffuser. An experiment was terminated either when the aufeis reached the down-stream (free overfall) end of the flume, or when the up-stream depth of aufeis approached the depth of the flume, whichever condition occurred first. As indicated in Table $I$, the time required for one experiment, from the first release of source water to the end of a test, varied from about 3 to $72 \mathrm{~h}$. At the end of each test, the aufeis was cut to expose and measure the layers of solid and slush ice that characterize crosssections of aufeis. The experimental apparatus and procedures have been described more fully by Schohl and Ettema (1986a, b).

\section{DESCRIPTION OF AUFEIS GROWTH}

The growth of a two-dimensional aufeis formation is portrayed sequentially in Figure 3 , in which the vertical scale is distorted by approximately one order of magnitude. In Figure 3, $T_{\mathrm{f}}$ refers to the freezing temperature of water. The normalization scales $t_{\mathrm{S}}$ and $\ell_{S}$, for which values are listed in Table I, are defined subsequently in section 4 .

TABLE I. LIST OF EXPERIMENTS

\begin{tabular}{|c|c|c|c|c|c|c|c|}
\hline \multirow{2}{*}{$\begin{array}{l}\text { Test } \\
\text { No. }\end{array}$} & \multicolumn{4}{|c|}{ Controlled variables } & \multicolumn{3}{|c|}{ Independent variables } \\
\hline & $Q_{0}$ & $T_{\mathrm{a}}$ & $T_{\mathrm{b}}$ & $S_{0}$ & $q_{0}$ & $\phi_{\text {wa }}$ & $\phi_{\mathrm{i} 0}$ \\
\hline & $1 \mathrm{~s}^{-1}$ & ${ }^{\circ} \mathrm{C}$ & ${ }^{\circ} \mathrm{C}$ & & $1 \mathrm{~s}^{-1} \mathrm{~m}^{-1}$ & $W m^{-2}$ & $W m^{-2}$ \\
\hline 1 & 0.00197 & -4.4 & -1.5 & 0 & 0.00392 & 34 & 89 \\
\hline 2 & 0.00195 & -5.0 & -2.7 & 0 & 0.00388 & 40 & 146 \\
\hline 3 & 0.00200 & -4.6 & -0.3 & 0 & 0.00398 & 36 & 17 \\
\hline 4 & 0.00203 & -9.5 & -1.3 & 0 & 0.00404 & 89 & 72 \\
\hline $4 b$ & 0.00200 & -9.6 & -1.3 & 0 & 0.00398 & 90 & 70 \\
\hline 5 & 0.00196 & -9.0 & -2.5 & 0 & 0.00390 & 83 & 128 \\
\hline 6 & 0.00199 & -9.4 & -0.2 & 0 & 0.00396 & 87 & 11 \\
\hline 7 & 0.00196 & -12.7 & -1.4 & 0 & 0.00390 & 132 & 72 \\
\hline 8 & 0.00200 & -12.1 & -2.7 & 0 & 0.00398 & 123 & 149 \\
\hline 9 & 0.00203 & -13.6 & -0.3 & 0 & 0.00404 & 144 & 17 \\
\hline 10 & 0.00409 & -5.1 & -1.4 & 0 & 0.00813 & 40 & 76 \\
\hline 11 & 0.00399 & -4.9 & -2.3 & 0 & 0.00793 & 38 & 117 \\
\hline 12 & 0.00392 & -5.0 & -0.2 & 0 & 0.00779 & 39 & 11 \\
\hline 13 & 0.00395 & -9.7 & -1.5 & 0 & 0.00785 & 91 & 76 \\
\hline 14 & 0.00397 & -9.6 & -2.3 & 0 & 0.00789 & 90 & 125 \\
\hline 15 & 0.00403 & -10.5 & -0.3 & 0 & 0.00801 & 101 & 16 \\
\hline 16 & 0.00399 & -12.5 & -1.5 & 0 & 0.00793 & 128 & 78 \\
\hline 17 & 0.00396 & -14.7 & -2.8 & 0 & 0.00787 & 162 & 143 \\
\hline 18 & 0.00395 & -14.6 & -0.3 & 0 & 0.00785 & 160 & 14 \\
\hline 19 & 0.00301 & -4.3 & -0.6 & 0 & 0.00598 & 33 & 35 \\
\hline 20 & 0.00297 & -5.1 & -2.2 & 0 & 0.00590 & 40 & 122 \\
\hline 21 & 0.00300 & -3.9 & 0.0 & 0 & 0.00596 & 29 & 0 \\
\hline 22 & 0.00298 & -10.5 & -1.1 & 0 & 0.00592 & 102 & 58 \\
\hline $22 \mathrm{a}$ & 0.00295 & -10.2 & -0.9 & 0 & 0.00586 & 97 & 45 \\
\hline 23 & 0.00294 & -9.8 & -2.8 & 0 & 0.00584 & 92 & 152 \\
\hline 24 & 0.00300 & -9.9 & -0.1 & 0 & 0.00596 & 93 & 6 \\
\hline $24 a$ & 0.00306 & -10.5 & -0.6 & 0 & 0.00608 & 101 & 35 \\
\hline 25 & 0.00302 & -13.0 & -1.0 & 0 & 0.00600 & 135 & 53 \\
\hline 26 & 0.00295 & -13.2 & -2.5 & 0 & 0.00586 & 139 & 135 \\
\hline 27 & 0.00299 & -12.6 & -0.2 & 0 & 0.00594 & 130 & 9 \\
\hline 28 & 0.00204 & -5.0 & -1.5 & 0.01 & 0.00406 & 39 & 86 \\
\hline 29 & 0.00203 & -13.6 & -0.8 & 0.01 & 0.00404 & 145 & 43 \\
\hline 30 & 0.00301 & -3.9 & -1.1 & 0.01 & 0.00598 & 29 & 59 \\
\hline 31 & 0.00299 & -11.4 & -1.4 & 0.01 & 0.00594 & 113 & 73 \\
\hline 32 & 0.00196 & -13.2 & -5.2 & 0 & 0.00390 & 139 & 163 \\
\hline 33 & 0.00201 & -5.1 & -4.7 & 0 & 0.00400 & 40 & 148 \\
\hline
\end{tabular}

Normalization scales
Test
duration

\begin{tabular}{rcccr}
$\mathrm{l}_{\mathrm{e} 0}$ & $t_{\mathrm{e} 0}$ & $\mathrm{l}_{\mathrm{S}}$ & \multicolumn{1}{c}{$t_{\mathrm{S}}$} & \\
$\mathrm{m}$ & $\mathrm{h}$ & $\mathrm{m}$ & $\mathrm{h}$ & $\mathrm{h}$ \\
& & & & \\
10.7 & 80.7 & 38.7 & 1062 & 35.7 \\
7.0 & 34.8 & 32.7 & 767 & 35.0 \\
25.5 & 455 & 37.4 & 975 & 21.3 \\
8.4 & 48.5 & 15.2 & 159 & 45.2 \\
8.3 & 48.4 & 14.8 & 153 & 32.7 \\
6.2 & 27.2 & 15.7 & 176 & 44.7 \\
13.5 & 127 & 15.2 & 162 & 43.5 \\
6.4 & 28.9 & 9.9 & 69.5 & 52.7 \\
4.9 & 16.6 & 10.7 & 80.6 & 72.3 \\
8.4 & 48.1 & 9.3 & 60.1 & 25.2 \\
23.4 & 187 & 68.3 & 1590 & 9.9 \\
17.1 & 102 & 69.6 & 1700 & 13.4 \\
51.3 & 937 & 65.9 & 1550 & 4.8 \\
15.8 & 87.7 & 28.9 & 296 & 20.2 \\
12.3 & 52.9 & 29.3 & 303 & 21.6 \\
22.9 & 181 & 26.6 & 244 & 13.5 \\
12.9 & 57.9 & 20.6 & 149 & 18.2 \\
8.6 & 26.1 & 16.2 & 92.1 & 24.1 \\
15.1 & 80.1 & 16.3 & 94.3 & 17.7 \\
29.4 & 401 & 61.4 & 1750 & 10.6 \\
12.2 & 69.4 & 48.8 & 1120 & 15.6 \\
66.2 & 2040 & 66.2 & 2040 & 7.7 \\
12.4 & 72.3 & 19.4 & 177 & 14.0 \\
13.8 & 89.9 & 20.3 & 194 & 19.2 \\
8.0 & 30.3 & 21.2 & 213 & 28.9 \\
20.1 & 188 & 21.4 & 214 & 10.4 \\
14.9 & 102 & 20.1 & 185 & 17.7 \\
10.7 & 52.7 & 14.8 & 102 & 23.5 \\
7.1 & 24.0 & 14.0 & 93.2 & 37.0 \\
14.3 & 95.6 & 15.2 & 109 & 20.3 \\
10.9 & 80.7 & 34.6 & 822 & 16.7 \\
7.2 & 35.2 & 9.3 & 59.1 & 43.7 \\
22.6 & 237 & 68.1 & 2150 & 2.7 \\
10.7 & 53.3 & 17.6 & 145 & 13.9 \\
4.3 & 13.1 & 9.3 & 62.1 & 70.4 \\
7.1 & 34.9 & 33.6 & 783 & 48.1
\end{tabular}




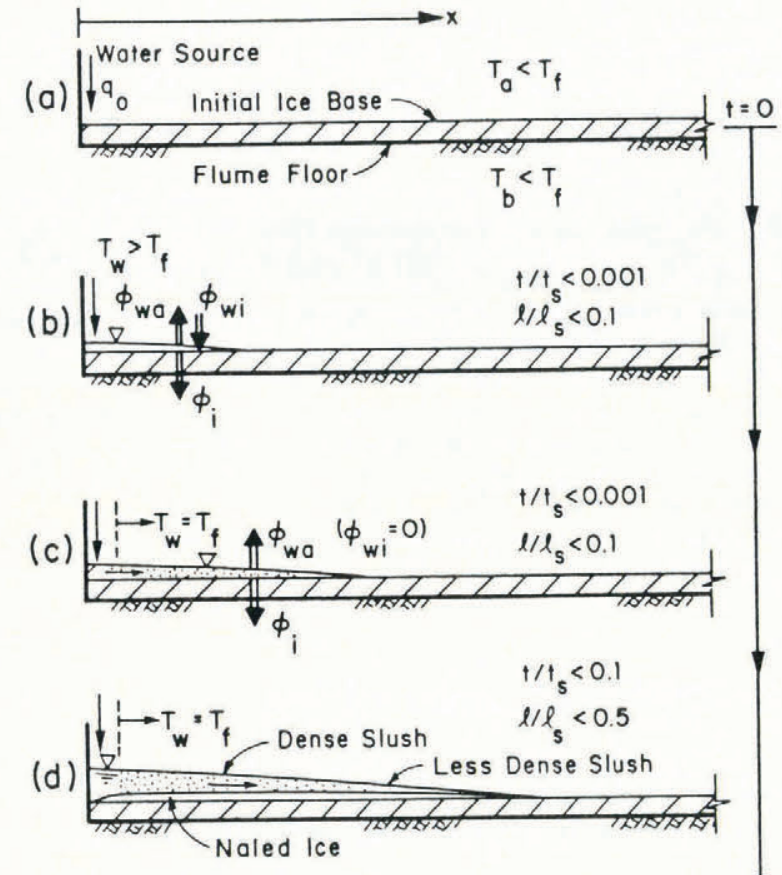

(e)

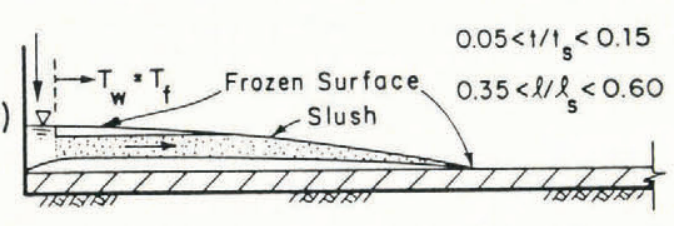

(f)
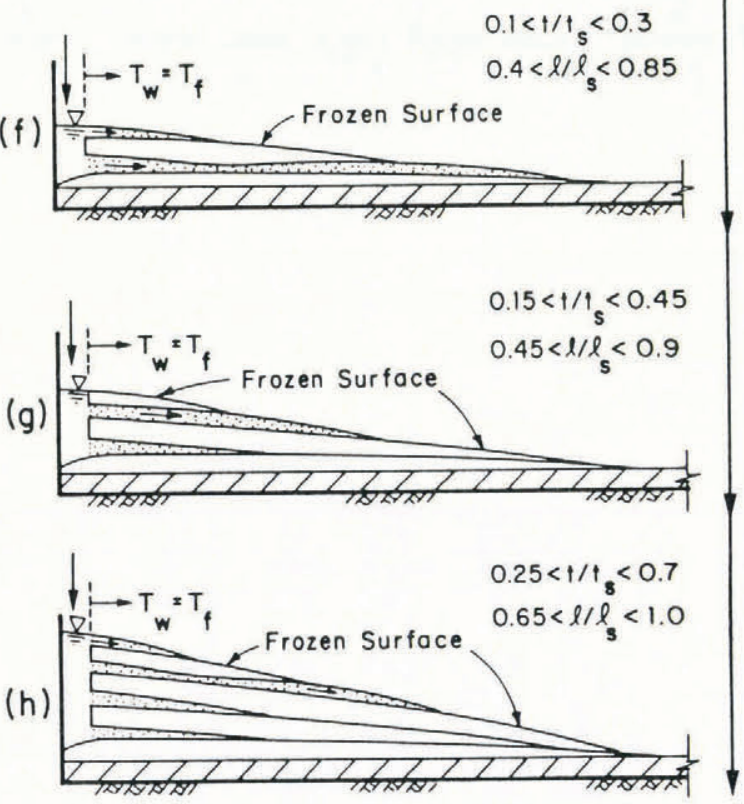

Fig. 3. Sketches illustrating two-dimensional aufeis formation.

Water cooled rapidly to its freezing temperature as it flowed over, and fed, an aufeis formation. Ice crystals, in the form of platelets anchored to the base ice surface, grew into the flow. The accumulation and growth of the ice platelets transformed the free-surface laminar flow of water into a flow through a porous medium composed of ice. Herein, this mixture of ice and flowing water is referred to as aufeis slush. During the experiments, aufeis slush eventually froze at its surface to form a solid crust of ice. Water continued to percolate through the layer of permeable slush, between the thickening ice crust over the slush and the underlying ice surface, until the permeability of the layer was sufficiently reduced to force water to flow over the frozen crust. Another slush layer then began to form. A second crust of ice would eventually form on the new surface flow. The continuing, cyclic process by which ice layers formed on the surface of slush layers resulted in the ice laminations that are a feature of aufeis cross-sections. Depending on the amount of time that the surface layers of ice had for thickening before they were covered by a fresh layer of slush, the laminations sometimes consisted entirely of solid layers of ice and sometimes consisted of alternating solid layers and layers of slush ice.

The flume constrained aufeis so that its initial growth was two-dimensional. However, the surface of the slush always began freezing and solidifying in the central third of its width rather than uniformly across the flume. As the central part hardened and thickened, constricting the flow through the underlying slush, the water was diverted to the sides of the flume so that the slush near the side walls continued to develop. The subsequent aufeis surface was uneven, with a rough, dry center and wet, slushy sides. Strictly speaking, the aufeis was no longer two-dimensional.

\section{NORMALIZED PARAMETERS INFLUENCING AUFEIS GROWTH}

The dependent variables that describe the growth of laterally confined aufeis, for example, the streamwise spread length $(\ell)$, the depth of ice-water slush on the surface $(d)$, or the slope of the aufeis surface $(S)$, depend on at least 14 independent variables. If a general dependent variable is designated as $\psi$, the following functional relationship can be written:

$$
\psi=f_{1}\left(x, t, q_{0}, \phi_{\mathrm{wa}}, \phi_{\mathrm{i}}, S_{0}, w, \rho_{\mathrm{i}}, \rho_{\mathrm{w}}, v, g, L, \alpha_{\mathrm{i}}, \alpha_{\mathrm{w}}\right)
$$

in which (see Fig. 2) $x$ is streamwise distance, $t$ is time, $q_{0}$ is unit discharge of water, $\phi_{\mathrm{wa}}$ and $\phi_{\mathrm{i}}$ are heat fluxes from aufeis surface to air and from surface layer to underlying aufeis, respectively, $S_{0}$ is slope of base on which aufeis forms, $w$ is lateral width of confined aufeis formation, $\rho_{\mathrm{i}}$ and $\rho_{\mathrm{w}}$ are densities of ice and water, respectively, $v$ is kinematic viscosity of water, $g$ is gravitational acceleration, $L$ is latent heat of water fusion, and $\alpha_{i}$ and $\alpha_{w}$ are thermal diffusivities of ice and water, respectively. Because temperature effects are incorporated into the heat-flux components, only three dimensions (length, mass, and time) are contained in the variables in Equation (1). Therefore, the 14 independent variables combine into 11 dimensionless groups, or normalized parameters.

Schohl and Ettema (1986a) derived, from conservation principles, depth-integrated equations for flow through aufeis slush. Rewritten in appropriate non-dimensional form, these equations indicate the correct form and importance of six of the 11 normalized parameters. The forms of the remaining five parameters are determined from dimensional analysis. In non-dimensional form, Equation (1) becomes

$$
\psi^{*}=f_{2}\left(\frac{x}{l_{\mathrm{e}}}, \frac{t}{t_{\mathrm{e}}}, S_{0}, \phi_{\mathrm{wa}}{ }^{*}, \Phi_{\mathrm{r}}, \frac{w}{l_{\mathrm{e}}}, \operatorname{Re}, \frac{d_{\mathrm{co}}}{l_{\mathrm{e}}}, \frac{v}{\alpha_{\mathrm{w}}}, \frac{\rho_{\mathrm{i}}}{\rho_{\mathrm{w}}}, \frac{\alpha_{\mathrm{i}}}{\alpha_{\mathrm{w}}}\right)
$$

in which $\psi^{*}$ is a normalized dependent variable, $\phi_{\mathrm{r}}=\phi_{\mathrm{wa}} /$ $\left(\phi_{\mathrm{wa}}+\phi_{\mathrm{j}}\right), \quad \phi_{\mathrm{wa}}{ }^{*}=\phi_{\mathrm{wa}}\left(10^{10}\right) / \rho_{\mathrm{w}} L^{3 / 2}$, where the constant $10^{10}$ is included merely for convenience, $d_{\text {co }}=\left(q_{0}{ }^{2} / g\right)^{1 / 3}$, the critical depth in a wide rectangular channel conveying a unit discharge $q_{0}$, and $\operatorname{Re}=q_{0} / v$, a Reynolds number.

In Equation (2), $\ell_{\mathrm{e}}$, termed the equilibrium length, is a length scale and $t_{\mathrm{e}}$ is a commensurate time-scale. The equilibrium length is a theoretical spread length for two-dimensional aufeis, derived by integrating the depthintegrated conservation of mass equation over the length of the aufeis:

$$
\ell_{\mathrm{e}}=\frac{q_{0} \rho_{\mathrm{w}} L}{\phi_{\mathrm{wa}}+\phi_{\mathrm{i}}}
$$

Subject to simplifying assumptions (see Schohl and Ettema, $1986 \mathrm{a}, \mathrm{b})$, for this length of spread, the source-water discharge is equal to, or in equilibrium with, the rate at which water is freezing along the aufeis. The time-scale $t_{\mathrm{e}}$ 
is defined in terms of the equilibrium length and the source-water discharge, $q_{0}$, as follows:

$$
t_{\mathrm{e}}=\frac{\ell_{\mathrm{e}}{ }^{2}}{100 q_{\mathrm{o}}} .
$$

With the value of 100 included, $t_{\mathrm{e}}$ represents the time required to cover a unit width of aufeis surface, $\ell_{\mathrm{e}}$ in length, with water of average depth $\ell_{\mathrm{e}} / 100$. For all the experiments, average water depths were several orders of magnitude less than values of $l_{\mathrm{e}}$.

The length scale $\ell_{S}$, referenced in Figure 3 , is defined by Equation (3) with $\phi_{\mathrm{i}}$ omitted. As aufeis accumulates layer by layer, the flow on its surface is often insulated from the heat flux $\phi_{\mathrm{i}}$. Consequently, the influence of $\phi_{\mathrm{i}}$, though initially significant, diminishes with aufeis thickening. The time-scale $t_{\mathrm{S}}$ is defined by Equation (4) with $\ell_{\mathrm{S}}$ substituted for $\ell_{\mathrm{e}}$.

Four of the 11 normalized parameters in Equation (2) may be omitted. The three parameters $v / \alpha_{\mathrm{w}}, \rho_{\mathrm{i}} / \rho_{\mathrm{w}}$, and $\alpha_{\mathrm{i}} / \alpha_{\mathrm{w}}$ are omitted because they are essentially constant for ice and water at a temperature near the freezing temperature. The parameter $d_{\mathrm{co}} / \ell_{\mathrm{e}}$ is omitted because it is associated with the acceleration term in the normalized momentum equation, and this term is negligible for seeping flow through aufeis slush. The functional relationship containing the key variables influencing aufeis growth is

$$
\psi^{*}=f_{3}\left(\frac{x}{l_{\mathrm{e}}}, \frac{t}{t_{\mathrm{e}}}, S_{0}, \phi_{\mathrm{wa}}{ }^{*}, \Phi_{\mathrm{r}}, \frac{w}{l_{\mathrm{e}}}, \mathrm{Re}\right) .
$$

The laboratory data on the spreading and thickening of aufeis are presented below in terms of the parameters in Equation (5). Because, as mentioned above, $\phi_{i}$ varied with $x$ and $t$, the initial values of $\ell_{\mathrm{e}}$ and $t_{\mathrm{e}}$, designated as $\ell_{\mathrm{e} 0}$ and $t_{\mathrm{e} 0}$, are used to normalize length and time variables.

\section{AUFEIS SPREADING}

In its initial phase of growth (Fig. 3b), aufeis spread relatively quickly. The growth and accumulation of ice platelets, which removed water mass and impeded the flow, gradually slowed aufeis spreading (Fig. $3 \mathrm{c}$ and d). As its surface froze into a layer of solid ice and a second layer of slush formed (Fig. $3 \mathrm{e}$ and $\mathrm{f}$ ), aufeis spread intermittently, stopping for periods of time and then continuing. Aufeis sometimes stopped spreading for relatively long periods of time when either its length approached its timevarying equilibrium length, or as the slush froze solid near its down-stream end (Fig. $3 \mathrm{~g}$ and h). Often, a fresh slush layer would later spread over and beyond the down-stream frozen surface, thereby continuing the aufeis expansion.

Aufeis spreading is described by Equation (5) with $\psi^{*}$ replaced by normalized spread length, $\ell / \ell_{\mathrm{e} 0}$. Because it is not a function of $x / l_{\mathrm{e}}$, spread length is influenced by six of the seven independent parameters in Equation (5). In Figure $4 a-c$, the experimental data for aufeis spreading on initially horizontal slopes $\left(S_{0}=0\right)$ are plotted against log of normalized time. In each plot, the values of base slope, $S_{0}$, and normalized heat flux, $\phi_{\mathrm{wa}^{*}}{ }^{*}$, are the same for all tests represented. Therefore, in accordance with Equation (5), the data in each plot should separate consistently with variations in $\Phi_{\mathrm{r}}, w / \ell_{\mathrm{e} 0}$, and $\mathrm{Re}$ for those cases in which these variables influence spreading. Curves representing the data plotted in Figure $4 a-c$ are plotted together in Figure 5 in order to illustrate the influence on aufeis spreading of the normalized surface heat flux, $\phi_{\text {wa }}{ }^{*}$.

During the early phase of aufeis growth (Fig. 3b-d), before the surface of the slush layer freezes solid, the normalized rate at which aufeis spreads is influenced by variations in $\phi_{\mathrm{wa}}{ }^{*}$ but it is not affected by variations in $\Phi_{\mathrm{r}}, w / \ell_{\mathrm{e} 0}$, or $\mathrm{Re}$, at least not for the ranges over which these parameters were varied during the experiments. Figure 5 illustrates the influence of variations in $\phi_{\mathrm{wa}}{ }^{*}$ on the early phase of spreading. Aufeis growing under colder air (larger $\phi_{\mathrm{wa}}{ }^{*}$ ) spreads slower because ice platelets accumulate faster. The insensitivity of the early spreading rate to variations in $\Phi_{\mathrm{r}}, w / \ell_{\mathrm{e} 0}$, or $\operatorname{Re}$ is illustrated in Figure $4 \mathrm{a}$, in which all the data collapse approximately to form a single curve, and
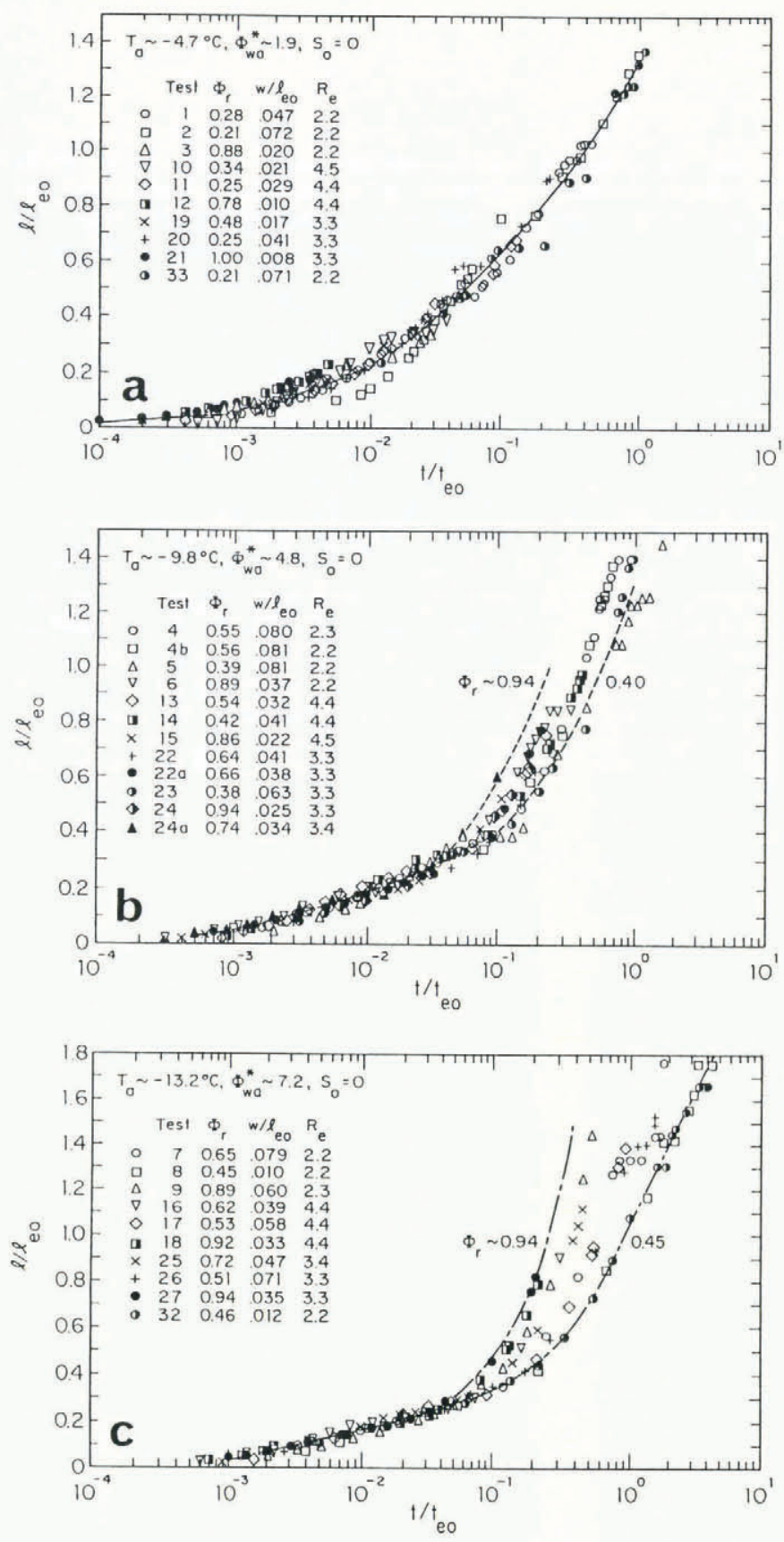

Fig. 4. Experimental data on aufeis spreading over a horizontal slope: (a) $T_{a}=-4.7^{\circ} \mathrm{C} ;$ (b) $T_{a}=-9.8^{\circ} \mathrm{C}$; (c) $T_{a}=-13.2^{\circ} \mathrm{C}$.

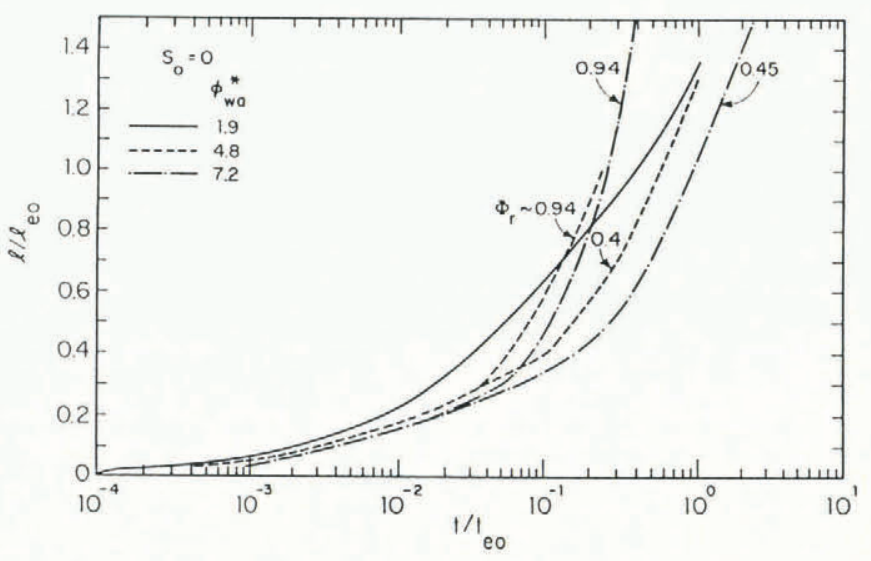

Fig. 5. Influences of $\phi_{w a}{ }^{*}$ and $\Phi_{r}$ on rate of aufeis spreading. 
in Figure $4 \mathrm{~b}$ and $\mathrm{c}$, in which the data for $t / t_{\mathrm{eo}}$ less than about 0.05 form a single curve. (The slush on aufeis grown in air temperatures near $-5^{\circ} \mathrm{C}$ did not freeze solid during the experiments.)

Figure $4 \mathrm{~b}$ and $\mathrm{c}$ show that the data eventually diverge from the common curves corresponding to the early phase of aufeis growth. Figures 4 and 5 together indicate that the point of divergence is influenced primarily by the heat flux $\phi_{\mathrm{wa}}$; that is, aufeis freezes over (or reaches the phase shown in Figure 3e) more rapidly when formed under conditions of larger $\phi_{\text {wa }}$. Figure $4 \mathrm{~b}$ and $\mathrm{c}$ show that, although other influences may be present, the point of divergence for each curve varies with $\Phi_{\mathrm{r}}$ : the larger the value of $\Phi_{\mathrm{r}}$, or the larger value of $\phi_{\mathrm{wa}}$ relative to the total heat loss $\phi_{\mathrm{wa}}+\phi_{\mathrm{i}}$, the sooner, in terms of $t / t_{\mathrm{e} 0}$, the data diverge from the initially common curve. Figure 5 shows that, for equal $\Phi_{\mathrm{r}}$, the data diverge more rapidly with larger values of $\phi_{\mathrm{wa}}{ }^{*}$, or $\phi_{\mathrm{wa}}$. The strong dependence of the divergence point on $\phi_{\mathrm{wa}}$ suggests examining the time of divergence in terms of time normalized by $t_{\mathrm{S}}$ (defined in section 4) rather than $t_{\mathrm{e} 0}$. The data suggest that the divergence point in each case corresponds to a unique, transition value of approximately 0.035 for $t / t_{\mathrm{S}}$. This value is determined by examining the geometric aspect ratio (average overall thickness, $q_{0} t / \ell$, divided by length of spreading, $\ell$ ) of aufeis as a function of $t / t_{\mathrm{s}}$, as shown in Figure 6. The transition time, the time at which the spread
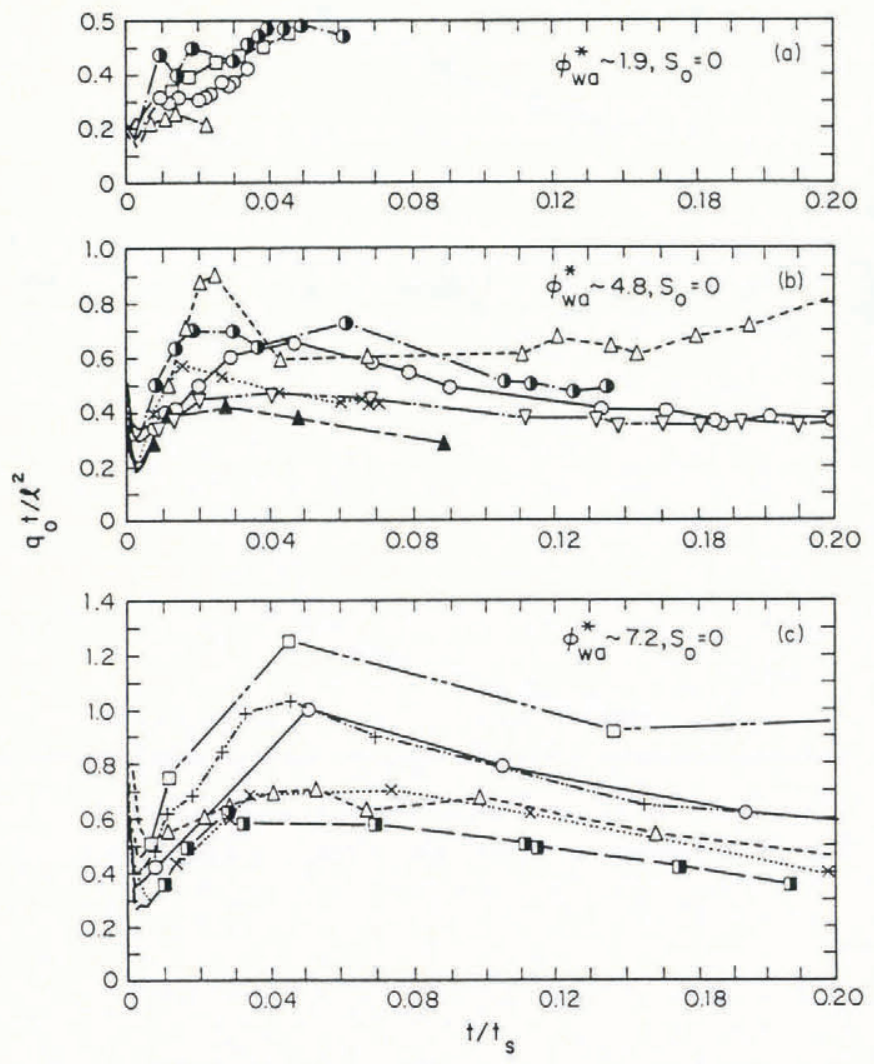

Fig. 6. Aspect ratio, defined as $q_{0} t / \mathrm{l}^{2}$, related to $t / t_{\mathrm{S}}$ (for (a), (b), and (c), symbols are defined in Figure $4 a-c$, respectively).

rate increases relative to the initial common rate, corresponds to the time at which the geometric aspect ratio reaches a maximum value. The value of $t / t_{\mathrm{s}}=0.035$ is the midpoint of the range $0.02-0.05$ over which transition times estimated from the data are scattered.

Apparently, near the transition value of $t / t_{\mathrm{S}}$, the magnitude of the heat flux $\phi_{\text {wa }}$ is effectively reduced over part of an aufeis formation's surface. Consequently, less of the water supplied to the aufeis freezes and the rate at which aufeis spreads is increased relative to the common curve representing the early phase of growth. The exact reason for the effective reduction in $\phi_{\text {wa }}$ when $t / t_{\mathrm{S}}$ passes 0.035 is not clear from the data. However, because the transition time is in terms of $t_{\mathrm{S}}$, the reduction must be related to the increasing accumulation of ice platelets. It seems that, as time increases beyond the transition value of $t / t_{\mathrm{S}}$, an increasingly significant part of the heat flux from the surface of aufeis acts to reduce the temperature within exisiting ice platelets rather than acting to cause more ice to grow within the slush. This effect leads to a decrease in the rate at which ice platelets grow. The transition value of $t / t_{\mathrm{S}}$ possibly represents the beginning of a continuous transition from the early, maximum rate of growth of ice platelets to the eventual slower rate of growth that occurs after the slush surface freezes over and partially insulates the underlying wet slush from the cold air above. If this is the case, the transition value of $t / t_{\mathrm{s}}$ may correspond to the start of the process by which the slush freezes solid.

At and beyond their divergence points, the curves in Figure $4 \mathrm{~b}$ and $\mathrm{c}$ do not, in all cases, consistently separate in accordance with variations in $\Phi_{\mathrm{r}}$. This is attributed primarily to the influence on aufeis spreading of lateral boundaries (flume side walls) after the slush on the aufeis surface begins to freeze solid. As already mentioned, the aufeis slush usually froze first along the central one-third of the flume's width. When this occurred, some of the up-stream water flow spread over the frozen area, while the remainder was diverted toward the flume's side walls, away from the frozen area. The water in the slush near the flume's side walls could flow past the frozen slush in the center of the flume and contribute to the spreading of the aufeis down- stream. The parameter $w / \ell_{\mathrm{e} 0}$ accounts, at least partially, for the influence of lateral boundaries. Figure $4 \mathrm{~b}$ and $c$ reveal that, if two sets of data with nearly the same value of $\Phi_{r}$ are compared (such as tests 5 and 23 in Figure $4 \mathrm{~b}$ or 17 and 26 in Figure 4c), the data associated with lesser values of $w / \ell_{\mathrm{e} 0}$ lie above the data for which $w / \ell_{\mathrm{e}}$ is larger. These results indicate that narrower aufeis formations spread faster, in normalized terms, than do wider aufeis formations.

For the relatively narrow range of Reynold's numbers, $\mathrm{Re}$, attained during the experiments, no consistent effect due to variations in $\mathrm{Re}$ are discernible in the data. The effect of $\mathrm{Re}$ would cause variations in the resistance to flow through aufeis slush, which is most significant during the early phase of growth. However, the data indicate that the early phase of aufeis growth is not affected by variations in $\mathrm{Re}$.

Data collected for two initial slopes of the laboratory flume are compared in Figure $7 \mathrm{a}$ and b. Figure 7a compares data from aufeis formed when $S_{0}=0.01$ and average $\phi_{\mathrm{wa}}{ }^{*}=1.75$ with a curve representing data from aufeis formed when $S_{0}=0$ and average $\phi_{\mathrm{wa}}{ }^{*}=1.9$. The data, which apply only to the early phase of aufeis growth, indicate that, all else equal, aufeis spreads faster on steeper slopes. Figure 7b compares data from aufeis formed when $S=0.01$ and average $\phi_{\mathrm{wa}}{ }^{*}=6.7$ with a curve representing data from aufeis formed when $S_{0}=0$ and average $\phi_{\mathrm{wa}}{ }^{*}=$ 7.2. These data indicate that, in colder air, aufeis may not spread significantly faster on steeper slopes. Compared with aufeis grown on horizontal surfaces, the aufeis grown in test 31 spread significantly faster while the aufeis grown in test 29 spread only slightly faster during the early phase of aufeis growth. During the later, layer-by-layer, phase of growth, the data in Figure $7 \mathrm{~b}$ suggest that aufeis formed on sloping surfaces may spread at about the same rates as aufeis formed, under similar conditions, on horizontal surfaces. However, the data suggest that the transition value of $t / t_{\mathrm{s}}$ may exceed 0.035 for aufeis grown on sloped surfaces, but further work is needed to verify this tentative conclusion.

\section{AUFEIS PROFILE}

Aufeis thickening is described by Equation (5) with $\psi^{*}$ replaced by normalized thickness, $s / l_{\mathrm{e} 0}$. The longitudinal profile of a two-dimensional formation of aufeis is described in terms of overall thickness, $s$, as a function of streamwise distance, $x$ (Fig. 2). Thickness $s$ includes only the water and ice that accumulated during a test; it does not include the thickness of the underlying ice base preformed over the flume floor.

As is the case for aufeis spreading, for times less than the transition value of $t / t_{\mathrm{S}}$ (about 0.035), aufeis is 

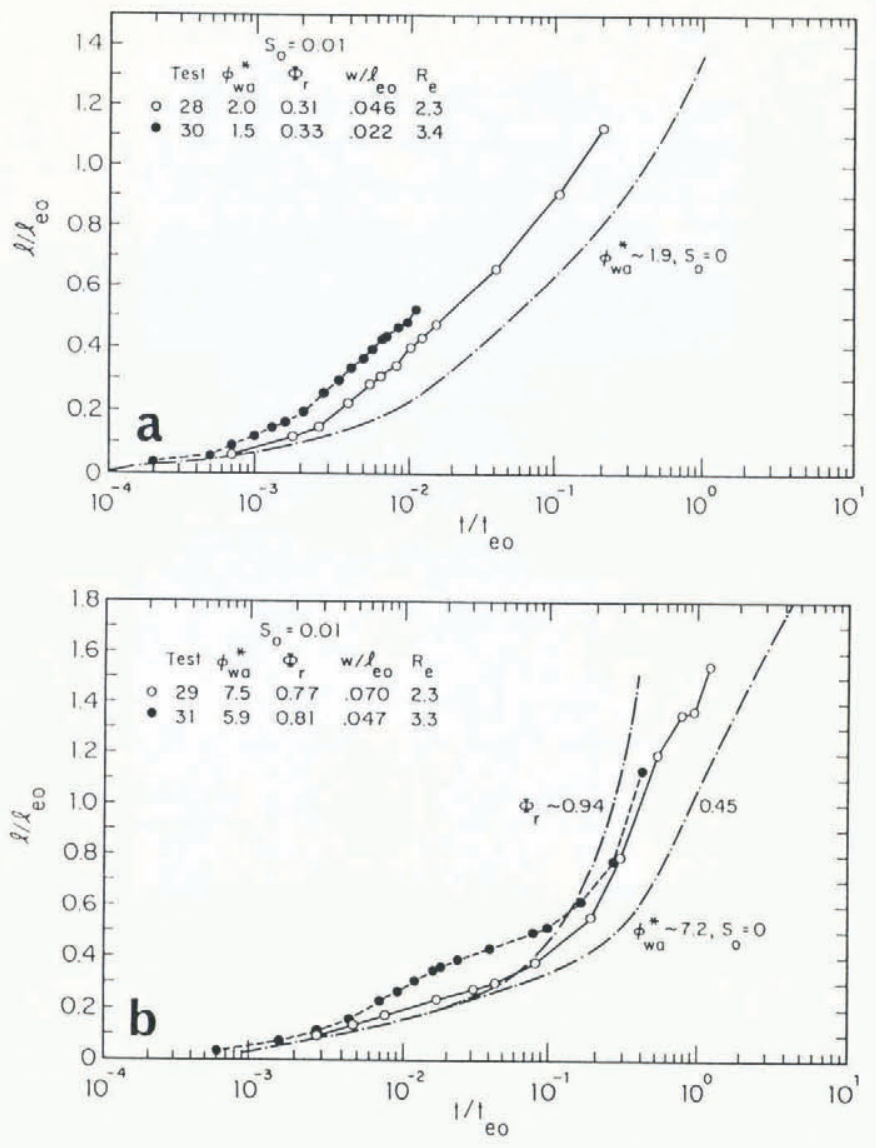

Fig. 7. Comparison of data on aufeis spreading over two slopes, $S_{0}=0$ and $0.01 ;$ (a) $\phi_{w a}{ }^{*}=1.5-1.9 ; \quad$ (b) $\phi_{w a}{ }^{*} \simeq 5.9-7.5$.

influenced by $\phi_{\mathrm{wa}}{ }^{*}$ but is not affected by variations in $\Phi_{\mathrm{r}}$, $w / \ell_{\mathrm{e} 0}$, or Re. This is evident in Figure $8 \mathrm{a}-\mathrm{c}$, which illustrate that the longitudinal shapes of aufeis formed in the flume for normalized times less than the transition time depend only on $t / t_{\mathrm{e} 0}$ and $\phi_{\mathrm{wa}}{ }^{*}$. Comparison of Figure $8 \mathrm{a}-\mathrm{c}$ reveals that, for a given value of $t / t_{\mathrm{e} 0}$, aufeis thickness relative to aufeis length increases with increasing $\phi_{\text {wa }}{ }^{*}$. In each plot in Figure 8 , the values of base slope, $S_{0}$, and normalized heat flux, $\phi_{\mathrm{wa}}{ }^{*}$, are the same for all data included. Therefore, the data in each plot represent aufeis spreading at identical normalized rates (see Figs 4 and 5). The indicated values of $t / t_{\mathrm{e} 0}$ are averages of the normalized times associated with the data on each curve. The point at which each curve intersects the abscissa corresponds to the appropriate spread length taken from Figure 4.

Figures $9 \mathrm{a}$ and $\mathrm{b}$, and $10 \mathrm{a}$ and $\mathrm{b}$ illustrate that, for times larger than the time associated with the transition value of $t / t_{\mathrm{S}}$, the shape of an aufeis formation is influenced by $\Phi_{\mathrm{r}}$ in addition to $t / t_{\mathrm{e} 0}, \phi_{\mathrm{wa}}{ }^{*}$, and $S_{0}$. For each plot in these figures the parameters $S_{0}, \phi_{\mathrm{wa}}{ }^{*}$, and $\phi_{\mathrm{r}}$ are the same for all data included. Consequently, if the possible influence of $w / \ell_{\mathrm{e} 0}$ and $\mathrm{Re}$ are neglected, the data in each plot represent aufeis formations spreading at identical normalized rates. For average $\phi_{\mathrm{wa}}{ }^{*}=4.8$ and a given value of $t / t_{\mathrm{e}}$, Figure $9 \mathrm{a}$ and $\mathrm{b}$ indicate that longer and thinner aufeis formations occur for larger values of $\Phi_{r}$. The same result is shown in Figure 10a and $\mathrm{b}$ for average $\phi_{\mathrm{wa}}{ }^{*}=7.2$

The possible influence on the data of the parameters $w / \ell_{\mathrm{e} 0}$ and $\mathrm{Re}$ is not evident in Figures $8-10$. However, the parameter $w / \ell_{\mathrm{e} 0}$ must influence the longitudinal shape of aufeis because, as discussed in section 5, it influences the length of aufeis spreading.

As illustrated by the data associated with the largest values of $t / t_{\mathrm{e} 0}$ in Figures 9 and 10 , the surface of aufeis of ten became uneven after the slush on its surface began to freeze solid. A feature of aufeis formation that is not evident in the profiles presented in Figures 8-10 is ledging, or the stepped profile which characterizes the front of many aufeis formations. In the refrigerated flume, under conditions of constant air temperature and water flow, ledging was observed only at the down-stream front of
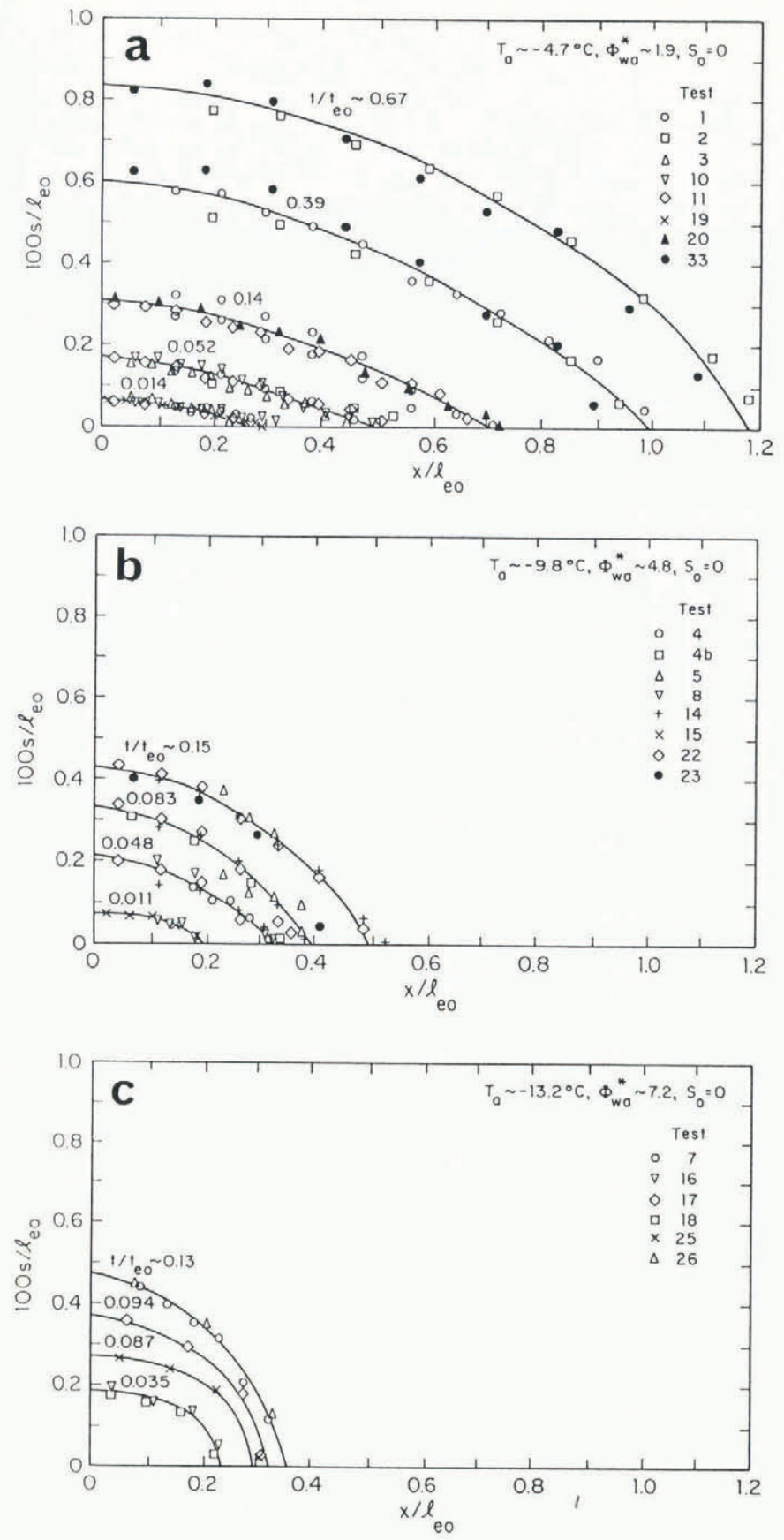

Fig. 8. Profiles of aufeis, presented in terms of normalized parameters for times not exceeding transition time: (a) $T_{a}=-4.7^{\circ} \mathrm{C}$; (b) $T_{a}=-9.8^{\circ} \mathrm{C}$; (c) $T_{a}=-13.2^{\circ} \mathrm{C}$.

spreading aufeis, as illustrated in Figure 11 (an aufeis formation formed under conditions similar to those in tests 8 and 32 ).

\section{AUFEIS LAMINATION THICKNESS}

As described in section 3, aufeis grows as successive layers of slush form and freeze solid into laminations of ice. Comparisons of measured values of lamination thickness with measured values of slush depth indicate that the thickness of an ice lamination is equal to the maximum depth attained by the slush from which the lamination developed. Therefore, data on slush depth indicate thicknesses of ice laminations in aufeis.

Besides being influenced by each of the key parameters given in Equation (5), the depth of a layer of aufeis slush may be affected by its position in the sequence of formation of slush layers. The data presented in this section were taken from the first layer of slush that developed after aufeis growth was initiated in the refrigerated flume. 

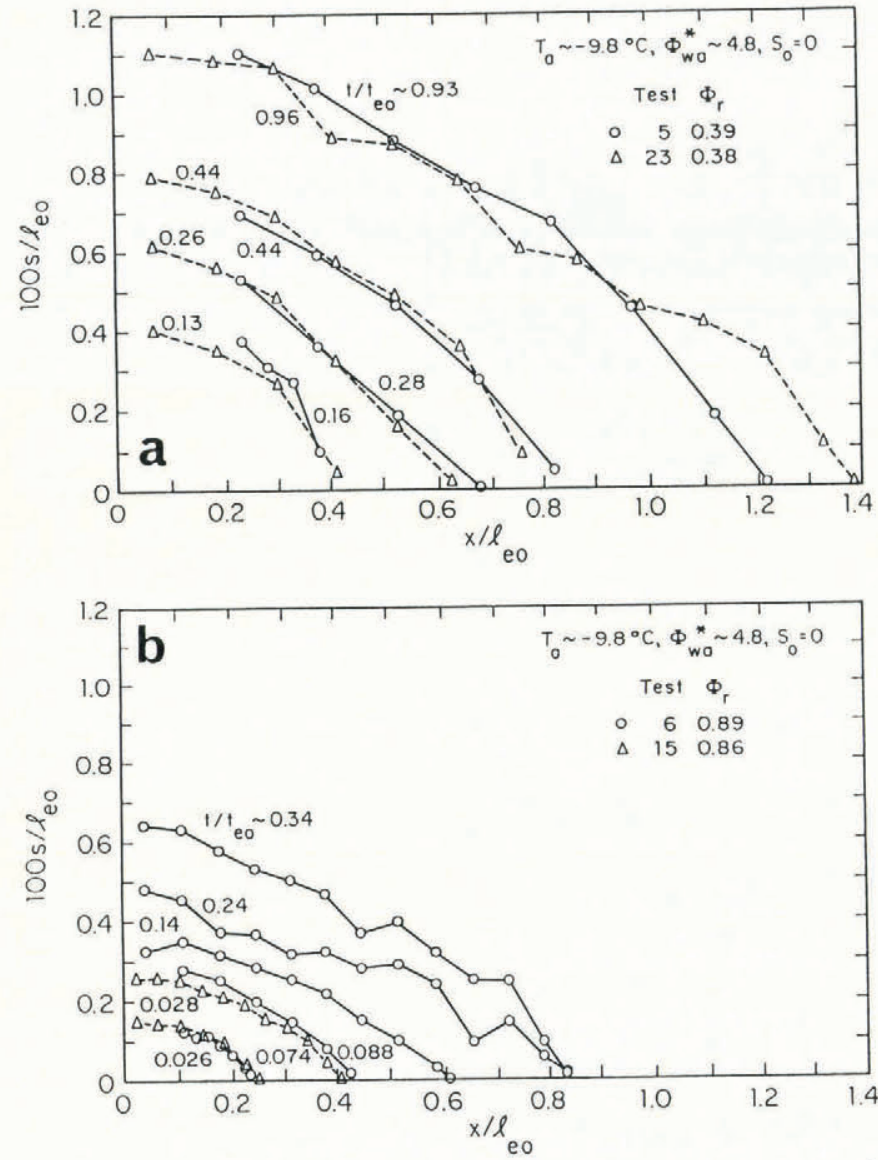

Fig. 9. Aufeis profiles, presented in terms of normalized parameters. for times exceeding transition time: $T_{a}=-9.8^{\circ} \mathrm{C} ;(a) \Phi_{r} \simeq 0.38 ;(b) \Phi_{r} \simeq 0.87$.
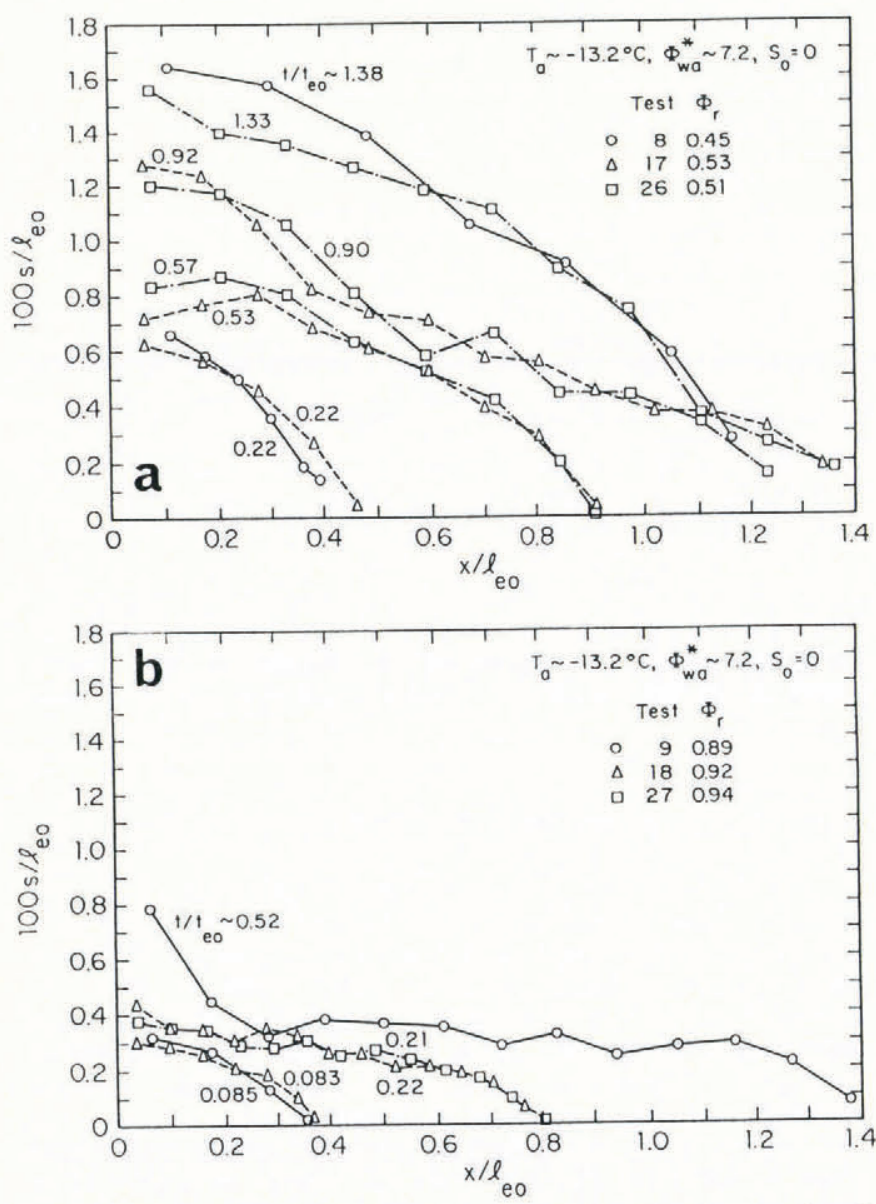

Fig. 10. Aufeis profiles presented in terms of normalized parameters, for times exceeding transition time: $T_{a}=-13.2^{\circ} \mathrm{C} ;$ (a) $\Phi_{r}=0.45-0.53 ;$ (b) $\Phi_{r}=0.89-0.94$.
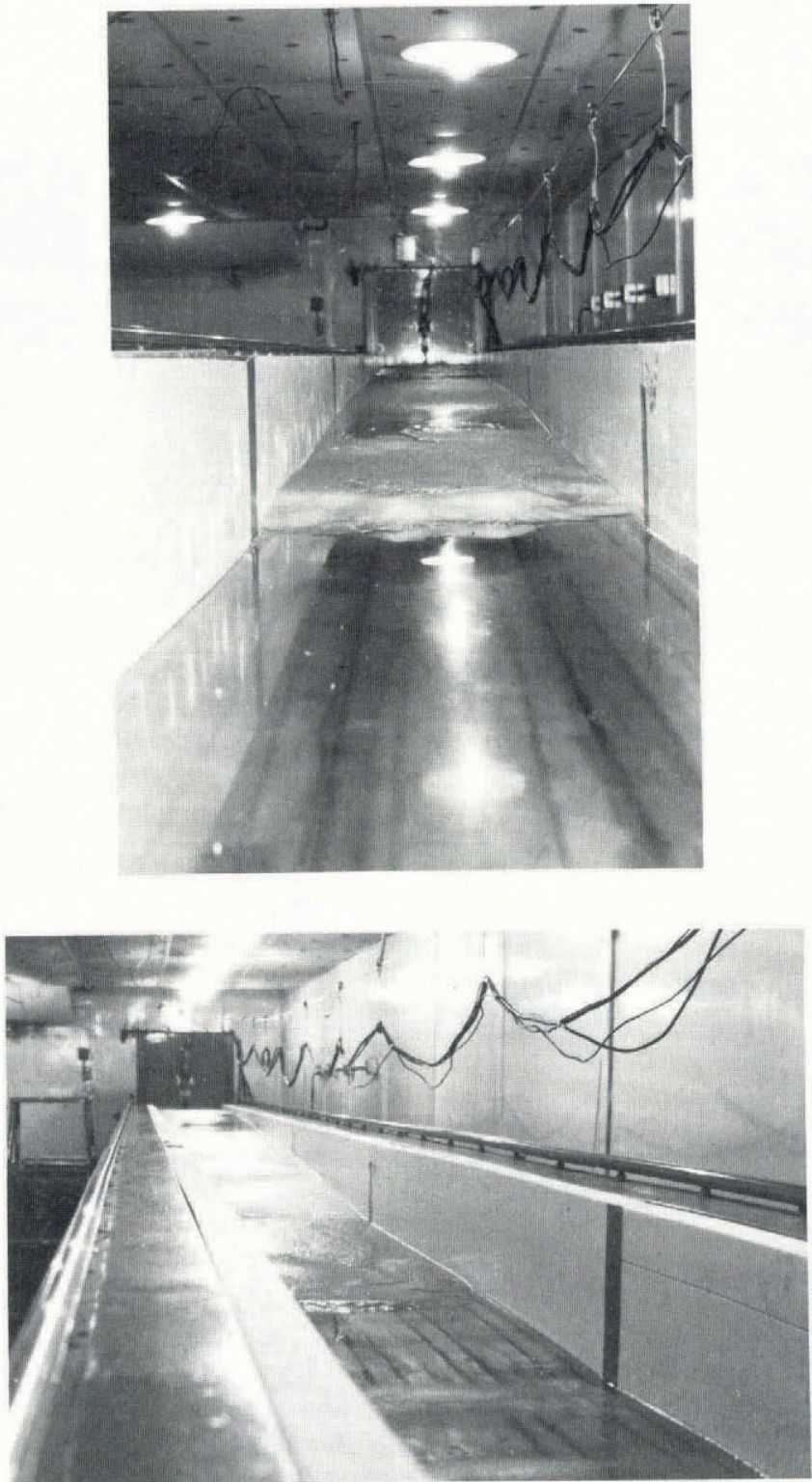

Fig. 11. Views of aufeis formed in the flume. Mild ledging is evident at the front of the aufeis.

The depth of the initial layer of slush, $d$, equals the thickness of the aufeis, $s$, minus the thickness of accumulated bottom ice, $\eta$ (Fig. 2). The normalized depth of slush, $d / \ell_{\mathrm{e} 0}$, varies with $x / \ell_{\mathrm{e} 0}, t / t_{\mathrm{e} 0}$, and $\phi_{\mathrm{wa}}{ }^{*}$ in essentially the same manner $s / l_{\mathrm{e} o}$ varies: slush depth was observed to decrease with increasing $x$ and increase with increasing $t$ and increasing $\phi_{\mathrm{wa}}{ }^{*}$. Schohl and Ettema (1986a), though, show that $d / l_{\mathrm{e}}$ depends on $\Phi_{\mathrm{r}}$ both before and after the transition value of $t / t_{\mathrm{S}}$, unlike both $\ell / \ell_{\mathrm{e} 0}$ and $s / l_{\mathrm{eo}}$

Table II indicates the maximum depths attained by slush layers near the up-stream end of the flume. These depths should equal the thickness of subsequent ice laminations. The time at which the slush up-stream reached a maximum depth ranged from $t / t_{\mathrm{S}}=0.06$ to 0.10 . At some time within this range, the surface of the slush up-stream

TABLE II. MAXIMUM DEPTH OF SLUSH UP-STREAM $\left(x / l_{\mathrm{e}_{0}}<0.1\right)$

$\begin{array}{ll}\phi_{\mathrm{wa}}{ }^{*} & \text { Range of } 100 d / l_{\mathrm{S}} \\ 1.9 & 0.10<100 d / l_{\mathrm{S}}<0.24 \\ 4.8 & 0.20<100 d / l_{\mathrm{s}}<0.24 \\ 7.2 & 0.26<100 d / l_{\mathrm{S}}<0.30\end{array}$


froze sufficiently to stop the thickening of the initial layer of slush. The maximum depth of slush decreased with increasing distance over aufeis but enough data to describe this variation are available only for $\phi_{w^{*}}{ }^{*}=7.2$, for which the following measurements were made: at $x / \ell_{\mathrm{e} 0}$ near 0.5 , the maximum $d / l_{S}$ ranged from 0.23 to 0.29 and at $x / \ell_{\mathrm{e} o}$ near 1.0 , the maximum $d / \ell_{\mathrm{S}}$ ranged from 0.14 to 0.23 .

Maximum slush depth, $d$, and corresponding time, $t$, are normalized by $\ell_{\mathrm{S}}$ and $t_{\mathrm{S}}$ rather than $\ell_{\mathrm{e}}$ and $t_{\mathrm{e}}$ in order to minimize the influence of $\Phi_{\mathrm{r}}$. In fact, the quantity of data is not sufficient to identify any consistent variations with $\Phi_{\mathrm{r}}$ in either the maximum value of $d / l_{\mathrm{S}}$ or in the corresponding value of $t / t_{\mathrm{S}}$.

The slush layers developing after the initial layer were nearly as deep as the initial layer. This observation suggests that little water flowed through slush layers under the surface of an aufeis formation. The succeeding layers formed from nearly as much water flow as did the initial layer.

\section{SCALES}

In section $4, \ell_{\mathrm{e} 0}$ and $t_{\mathrm{e} 0}$, the initial values of $\iota_{\mathrm{e}}$ and $t_{e}$, are introduced as length and time scales for normalizing and, therefore, describing aufeis formation. Only the initial values of $\ell_{\mathrm{e}}$ and $t_{\mathrm{e}}$ are convenient to use because the heat flux to the frigid base, $\phi_{i}$, diminishes over time, gradually increasing the values of $\ell_{\mathrm{e}}$ and $t_{\mathrm{e}}$ until, in the limit, these scales are equivalent to $\ell_{\mathrm{S}}$ and $t_{\mathrm{S}}$, which are length and time scales derived by neglecting $\phi_{\mathrm{i}}$. The usefulness of $\ell_{\mathrm{e}}$ and $t_{\mathrm{e}}$ in describing aufeis geometry, particularly during the early phase of aufeis growth, is verified in the figures presenting the laboratory data on spreading and thickening of two-dimensional aufeis (e.g. Fig. 4). Use of $\ell_{\mathrm{S}}$ and $t_{\mathrm{S}}$, as is done in Figure 3, may be appropriate for describing the layer-by-layer phase of aufeis growth, after the transition time has passed, or, more generally, when $\phi_{\text {wa }}$ is much greater than $\phi_{\mathrm{i}}$. By themselves, however, neither $\ell_{\mathrm{e} 0}$ and $t_{\mathrm{e} 0}$ nor $\ell_{\mathrm{S}}$ and $t_{\mathrm{S}}$ are sufficient to describe aufeis formation.

The scales $\ell_{\mathrm{e} 0}$ and $t_{\mathrm{e} 0}$ are derived from integration of the conservation-of-mass equation for flow over the surface of aufeis. Consequently, these scales normalize differences in total mass between aufeis formations, where normalized total mass per unit width of aufeis, $M^{*}$, is defined as follows:

$$
M^{*}(t)=\frac{\rho_{\mathrm{w}} q_{0} t}{\rho_{\mathrm{w}^{\ell} \mathrm{e}^{2}}}=\frac{t}{100 t_{\mathrm{e} 0}} .
$$

As is evident from Equation (6), at any given value of normalized time, $t / t_{\mathrm{e} 0}$, all two-dimensional aufeis formations consist of the same quantity of normalized mass. Furthermore, for all aufeis formations spreading at the same normalized rate $\left(\ell / \ell_{\mathrm{e} 0}\right.$ as a function of $\left.t / t_{\mathrm{e} 0}\right)$, the division of the total normalized mass into ice mass, $M_{\mathrm{i}}^{*}$, and water mass, $M_{\mathrm{w}}{ }^{*}$, is the same. This is evident from the following equation for normalized ice mass, $M_{\mathrm{i}}^{*}$, derived by Schohl and Ettema (1986a) for constant total heat flux, $\phi_{\mathrm{wa}}+\phi_{\mathrm{i}}$ :

$$
M_{\mathrm{i}}{ }^{*}(t)=\frac{1}{100} \int_{0}^{\ell / \ell}\left[\frac{t}{t_{\mathrm{e} 0}}-\frac{t_{\ell}(x)}{t_{\mathrm{e} 0}}\right] d\left[\frac{x}{\ell_{\mathrm{e} 0}}\right]
$$

in which $M_{\mathrm{i}}$ is ice mass per unit width and $t_{\ell}(x)$ is time at which the spreading, down-stream edge of aufeis reaches streamwise position $x$. Because the mass of unfrozen water is the difference between the total mass and the total ice mass, aufeis formations consisting of the same $M^{*}$ and $M_{\mathrm{i}}{ }^{*}$ also contain the same $M_{\mathrm{w}}{ }^{*}$.

While the total quantity of ice is accounted for using the scales $\ell_{\mathrm{e} 0}$ and $t_{\mathrm{e} 0}$, they do not take into account the division of ice into ice platelets, which grow to balance the heat flux $\phi_{\text {wa }}$, and bottom ice, which grows to balance the heat flux $\phi_{\mathrm{i}}$. Effects that depend on one or the other of these heat fluxes, rather than the total heat flux, vary with $\Phi_{\mathrm{r}}$ and $\phi_{\mathrm{wa}}{ }^{*}$. For example, Figures 4 and 5 show that aufeis formations spread at different rates for different values of $\Phi_{\mathrm{r}}$ and $\phi_{\mathrm{wa}}{ }^{*}$. The effects on aufeis formation of both $\phi_{\mathrm{r}}$ and $\phi_{\mathrm{wa}}{ }^{*}$ are attributable to two influences of $\phi_{\mathrm{wa}}$ that are separate from the influences of the total heat flux, $\phi_{\mathrm{wa}}+\phi_{\mathrm{i}}$. First, the ice platelets that grow to balance $\phi_{\mathrm{wa}}$, or $\phi_{\mathrm{wa}}{ }^{*}$, increase resistance to water flow and, thereby, impede aufeis spreading. Secondly, of the total heat flux, the time at which the slush on aufeis begins to freeze solid is influenced primarily by $\phi_{\mathrm{wa}}$, an influence appropriately represented by the ratio of $\phi_{\text {wa }}$ to the total heat flux, or $\Phi_{\mathrm{r}}$.

Figure 8 shows that aufeis formations spreading at the same normalized rate have the same longitudinal shape at any given time, $t / t_{e 0}$, before the transition time has passed. That is, not only do they have the same normalized mass, as mentioned above, but the distribution of the mass over $x / \ell_{e 0}$ is also the same. However, Figure 8 also shows that, before the transition time has passed, aufeis thickness relative to aufeis length increases with increasing $\phi_{\mathrm{wa}}{ }^{*}$. Explained within the context of the current discussion, different aufeis formations have the same total mass at a common value of $t / t_{\mathrm{e} 0}$, but their normalized spread lengths, $\ell / \ell_{e 0}$, are different, depending on $\phi_{w_{a}}{ }^{*}$. For twodimensional formations, equivalence in total mass corresponds to equivalence in the cross-sectional areas under the curves (Fig. 8) delineating the shapes of different aufeis formations. Consequently, as would be expected, at the same value of $t / t_{\mathrm{e} 0}$, a shorter aufeis formation is thicker than a longer one.

The foregoing discussion deals with definition of appropriate scales for describing two-dimensional formations of aufeis. For description of three-dimensional formations, such as may form at the exit of a culvert or over a broad, shallow river, different length and time scales would apply. Appropriate scales would entail use of a theoretical spread area from which would be determined length as well as time-scales.

\section{CONCLUSIONS}

The many factors influencing aufeis growth reduce to a set of seven key independent parameters as expressed in Equation (5).

A transition time is identified which apparently coincides with the beginning of the processes by which the initial layer of ice-water slush on aufeis freezes solid. In terms of the time-scale $t_{\mathrm{S}}$, this transition time is approximately $t / t_{\mathrm{S}}=0.035$. However, the transition time may vary slightly with $\phi_{\mathrm{wa}}{ }^{*}$ and $\phi_{\mathrm{r}}$, and significantly with $S_{0}$.

The early phase of aufeis formation, before the transition time has passed, is influenced by only the first four key parameters listed in Equation (5). For the same values of $S_{0}$ and $\phi_{\mathrm{wa}}{ }^{*}$, aufeis formations in their early phase spread at the same normalized rate (Fig. 4) and have the same normalized shape (Fig. 8). Aufeis formed under large values of $\phi_{\mathrm{wa}}{ }^{*}$ spreads more slowly and, consequently, is shorter and thicker than aufeis formed under smaller values of $\phi_{\text {wa }}{ }^{*}$ (Figs 6 and 8). The small amount of data collected from aufeis formed on a sloped surface suggests that, during the early phase of formation, aufeis spreads faster on steeper surfaces (Fig. 7).

After the transition time has passed, $\Phi_{\mathrm{r}}$ and $w / \ell_{\mathrm{e}}$ of the remaining three parameters in Equation (5) come into play. The normalized rate of aufeis spreading increases with increasing $\Phi_{\mathrm{r}}$ and with decreasing $w / \ell_{\mathrm{e}}$ (Fig. 4). At a given value of $t / t_{\mathrm{e}}$, aufeis forming under large $\Phi_{\mathrm{r}}$ is both longer and thinner than aufeis formed under smaller $\Phi_{\mathrm{r}}$ (Figs 4,9 , and 10). The data from aufeis formed on a sloped surface suggest that, after the transition time has passed, the rate at which aufeis spreads may no longer depend on slope, $S_{0}$ (Fig. 7).

Although it is possible that variations in Reynolds number, $\mathrm{Re}$, also influence aufeis formation, for the relatively narrow range of Reynolds numbers attained during the experiments, no consistent effect is discerned.

The thickness of aufeis laminations corresponds to the thickness attained by slush layers before they freeze solid.

The present study is limited to two-dimensional aufeis formations such as those, for example, that may develop in culverts. Considerable work remains before relationships are 
available for use in the design of culverts and other watercourses for the possibility of aufeis formation. Further work is also needed on aufeis formations which spread and thicken three-dimensionally.

\section{ACKNOWLEDGEMENT}

This research was supported by the U.S. National Science Foundation (NSF grant CEE81-09252).

\section{REFERENCES}

Alekseyev, V.R., and others, eds. 1973. Siberian naleds.
CRREL Draft Translation 399.

Ashton, G.D., ed. 1986. River and lake ice engineering. Littleton, CO, Water Resources Publications.

Carey, K.L. 1973. Icings developed from surface water and ground water. CRREL Monogr. III-D3.

Kane, D.L. 1981. Physical mechanics of aufeis growth. Can. J. Civ. Eng., 8, 186-195.

Schohl, G.A. and R. Ettema. 1986a. Naled ice growth. Iowa City, IA, University of Iowa, Institute of Hydraulic Research. (Report 297.)

Schohl, G.A. and R. Ettema. 1986b. Theory and laboratory observations of naled ice growth. J. Glaciol., $32(111), 168-177$.

MS. received 7 November 1989 and in revised form 11 April 1990 